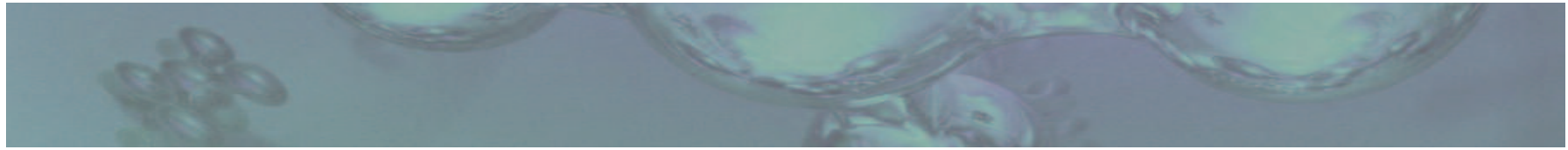

\title{
EURAMET: European Association of National Metrology Institutes
}

\section{Leslie R. Pendrill}

Abstract: Intensified cooperation amongst the national metrology institutes of Europe in all their fields of activity, from metrological research to calibration services, is a response to increased needs of society for traceable measurement, not only in the traditional areas (trade, manufacturing) but also in meeting the 'Grand Challenges' of modern society, such as Energy \& the Environment; Health and Security, often in combination with the enabling technologies. European metrology had been coordinated successfully since 1987 by the European Association of National Metrology Institutes (EUROMET) but with increased integration of national programmes, a change of organisational form became necessary and since 2007 EURAMET e.V. is its successor as the Regional Metrology Organisation (RMO) of Europe. Increased cooperation means not merely adding together the sum of the national metrology programmes but even integrating resources, at least partially, in a truly regional programme. Alongside other EURAMET developments such as the European Metrology Research Programme and increasing support to metrological infrastructures reported elsewhere in this journal, the present paper will highlight other important EURAMET activities:

- International recognition of national measurement standards and of the Calibration and Measurement Capabilities (CMC) of its members.

- Metrology knowledge exchange both nationally and in the region as a whole.

Progress in the new EURAMET organisation enabling Europe to respond to the growing demands for cutting-edge metrology as a tool for innovation, scientific research and support for policy, particularly in emerging technological areas and in meeting the major challenges of society will be reported by the new EURAMET Chairperson.

\section{EURAMET as a Regional Metrology Oraganisation}

Regional metrology organisations, such as the European Association of National Metrology Institutes (EURAMET) [1], are arenas for cooperation in National Metrology. Cooperation amongst national metrology institutes and designated institutes is necessary in all their fields of activity, from metrological research to the provision of calibration services, in response to increased needs of society for traceable measurement. Such needs arise not only in traditional areas (trade, manufacturing, etc.) but also in meeting some of the 'Grand Challenges' of modern society, such as Energy \& the Environment; Health; Security; etc., often in combination with the enabling technologies (such as nanotechnology and biotechnology).

\section{Leslie R. Pendrill}

EURAMET e.V. - European Association of National Metrology Institutes

SP Technical Research Institute of Sweden

Measurement Technology, Box 857

SE-50115 Borås (SE), Sweden

Email: chairperson@euramet.org
The European Association of National Metrology Institutes is a Regional Metrology Organisation (RMO) of Europe. It coordinates the cooperation of National Metrology Institutes (NMI) and associated institutes of Europe in the following fields of activity:

A. Traceability of Measurements to the International System of Units (SI)

B. International Recognition

1. National measurement standards.

2. Calibration and Measurement Capabilities (CMC) of the members.

C. Knowledge Exchange \& Infrastructural Support in Metrology

D. Research in Metrology

3. European Metrology Research Programme (EMRP).

4. Technical Committees R\&D projects.

This paper reviews progress in the last year in EURAMET as a whole.

Significant progress in strategic areas (C) and (D) include, respectively, the creation of a EURAMET Focus Group for "Facilitating National Metrology Infrastructure Development" and the implementation of a major European Metrology Research Programme, as will be reported elsewhere in this 


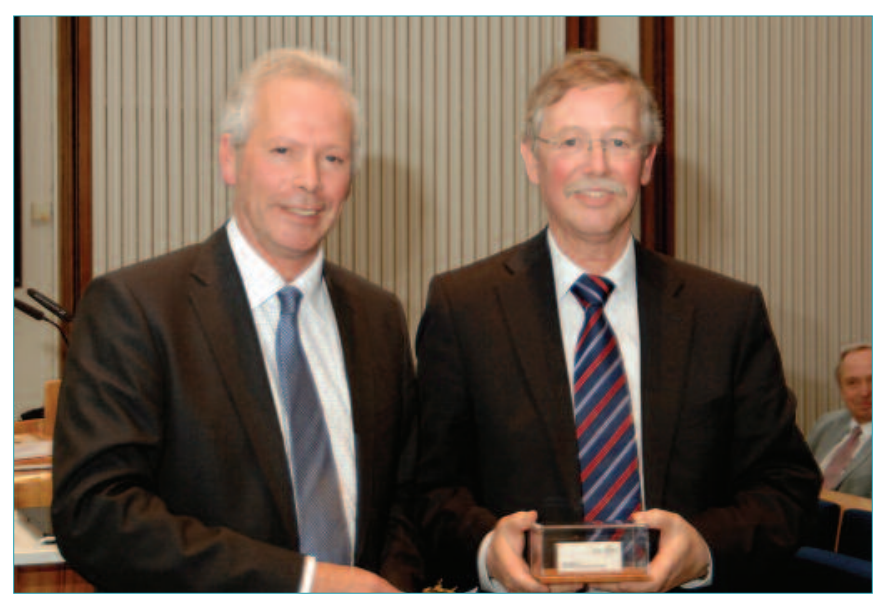

Figure 1. EURAMET Chair Prof. Michael Kühne (right) presented with EURAMET ceremonial gauge block by EURAMET Chairperson-elect Leslie Pendrill.

journal by my colleagues, respectively, EURAMET Secretary Wolfgang Schmid \& Vice-chair Arnold Leitner [2] and EURAMET EMRP Programme Manager Andy Henson [3], in two separate papers from the 2009 NCSLI Workshop and Symposium.

With increased integration of national metrology programmes, a more formal organisation of European metrology, which had been coordinated successfully since 1987 by EUROMET, became necessary. In July 2007 EURAMET e.V. was formed as a registered association of public utility under German law. With currently over 100 member and associate organisations from 33 European countries, EURAMET members employ about 4000 persons, about 2000 persons of whom work on research \& innovation (R\&I) activities and spend about $200 \mathrm{M} €$ per year (50\% of total budget) on metrological R\&I. EURAMET is characterised by a wide diversity amongst its members, with a factor of 200 between the research budgets of the largest and smallest NMIs in the region. It is worthwhile pointing out that this does not mean that the larger NMI is 200 times better in research than the smaller NMI; simply that the number of projects per institute is rather different. Indeed, in individual EURAMET projects, the research capabilities of the different NMIs are often comparable, irrespective of the size of the home institute.

This paper is authored by the new EURAMET Chairperson, Leslie Pendrill, from the Swedish national metrology institute, hosted by SP Technical Research Institute of Sweden. The previous Chair, Prof Michael Kühne of the German national metrology institute Physikalisch-Technische Bundesanstalt (Fig. 1), has now moved to the Bureau International des Poids et Mesures (BIPM) in Sevres, France where he becomes Deputy Director in preparation for taking over as BIPM Director in 2010.

Alongside high-profile developments, such as the initiation of the European Metrology Research Programme [3] and increasing support to metrological infrastructure development [2], this paper will highlight other important EURAMET activities, particularly continued work promoting the Mutual Recognition Arrangement and identifying opportunities for intensified metrology knowledge exchange, both amongst NMIs and with major stakeholder groups.

\section{International Recognition (Activity B)}

In recent years, the EURAMET organisation has expanded to encompass to date member organisations and associates from 37 European countries. Work in EURAMET continues within the framework of the Mutual Recognition Arrangement; overseeing the calibration \& measurement capabilities; quality management systems; and key or supplementary comparisons engaging its growing membership, both nationally and Europe-wide.

These activities, alongside the extensive efforts made in connection with key and supplementary interlaboratory comparisons, cover 'internal' quality management, as well as the important and wider role of quality-assured measurement in conformity assessment of products and services.

\subsection{Quality Management Reviews and Membership Issues}

The maintenance and review of the quality management systems for EURAMET e. V. and its 100+ members and associate organisations is a major activity:

- In conjunction with the Mutual Recognition Agreement of the International Committee for Weights and Measures (CIPM MRA) aimed at demonstrating the equivalence of different national metrology systems.

- As a backbone of the EURAMET regional organisation itself, both to ensure proper management of what has become a major multi-national body, as well as to ensure reliable handling of major programmes, such as the European Metrology Research Programme.

During the past year, EURAMET has focused on key aspects of quality management reviews, including the publication of a new Guide "EURAMET procedures and review criteria for CMCs" [4] as well as working with new criteria for accepting members and associates and procedures for on-site peer review visits. Greater use of on-site peer review within EURAMET is more likely in future, as a means of strengthening the robustness of activities in the framework of the CIPM MRA. Criteria for associate membership of EURAMET are being reviewed.

Cyprus became the $33^{\text {rd }}$ EURAMET Member 1st January 2009, marking that all the former EUROMET countries are now part of EURAMET.

\subsection{Role of Quality-assured Measurements in Conformity Assessment}

One occasion where the role of quality-assured measurement in conformity assessment has been recently highlighted was on the occasion of World Metrology Day 2009 (WMD 2009) under the theme "Measurements in Commerce." [5]

Echoing the words of the BIPM Director and the WMD Team on this occasion [5]: When we trade, we measure, and the international trading system relies on these measurements being "right" wherever they are made. But how do we know that these measurements are "right"? That is the job of metrologists - scientists who specialize in measurement techniques and who provide the international framework for accurate measurement that industry, legislators, regulators and the general public can rely upon.

Reliable measurements should give substantially the same answer wherever they are made. This is achieved by ensuring 


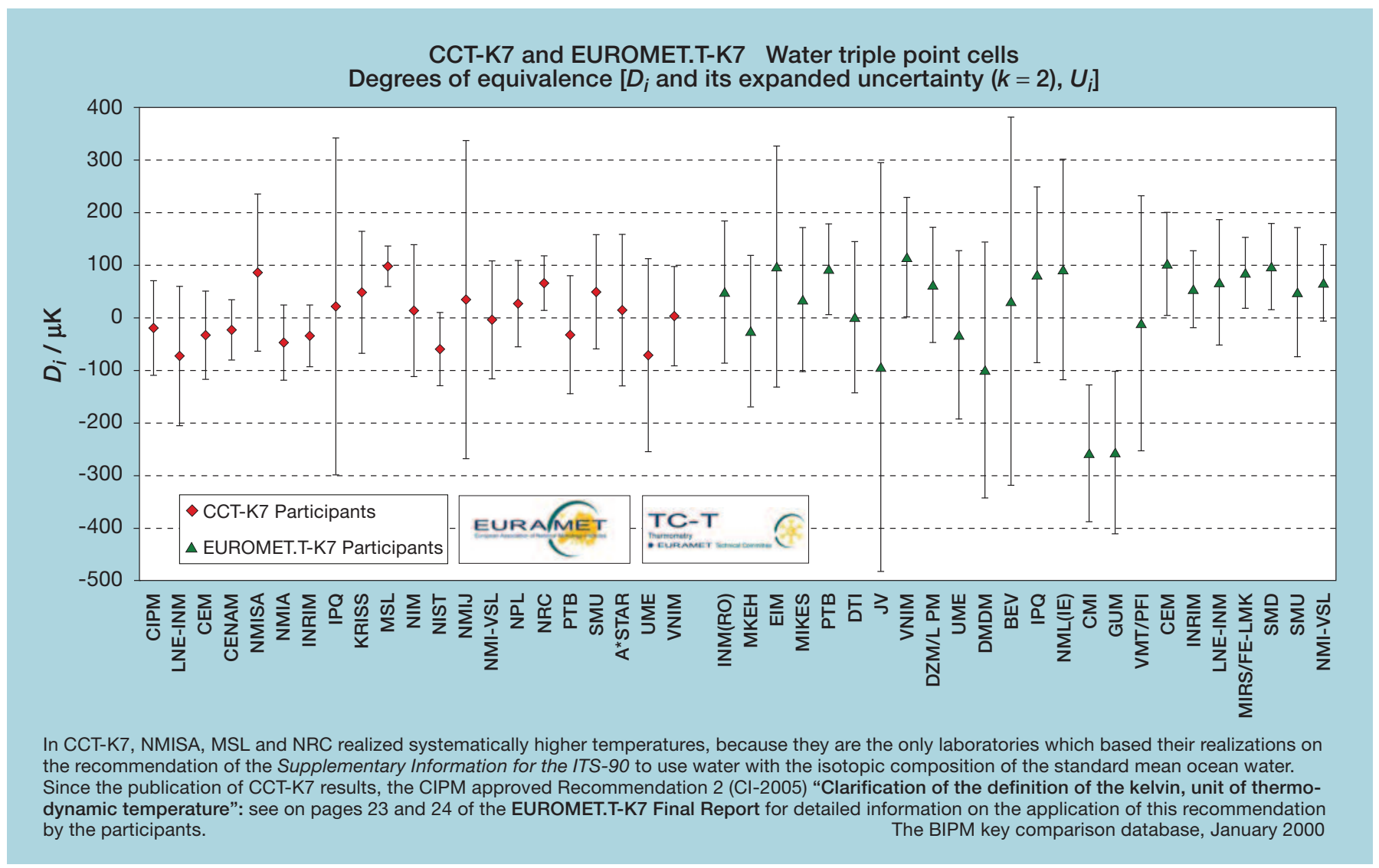

Figure 2. Some results of EURAMET.T-K7 key comparison of water triple point cells. [7]

traceability to the International System of Units referred to as the SI, covering the base units (metre, kilogram, second, kelvin, candela, ampere, mole) and the derived units. National realizations of these Units are maintained and calibration services are provided by National Metrology Institutes and their regional metrology organisations, such as EURAMET. These work together with other organisations such as standardisation, accreditation and legal metrological bodies in providing the technological infrastructure in support of trade and other areas of conformity assessment. The 100+ EURAMET members provide essential dissemination of metrological traceability and measurement know-how to many thousands of secondary calibration laboratories and conformity assessment bodies such as testing labs in many sectors and technologies.

No measurement is absolutely perfect, and a second important job of a metrologist is in the estimation of measurement uncertainties. This quality factor is an essential measure of the reliability of a measurement result which in turn determines the reliability of any decision based on measurement, for instance, to ensure fair trade. Optimised levels of measurement uncertainty are those where the costs of testing are balanced against the consequence costs of incorrect decisions of conformity, directly based on the impact and utility of each test and product assessment.

EURAMET has joined the BIPM and the World Metrology Day 2009 project team in celebrating the success of the first decade of a global scheme, the CIPM Mutual Recognition Arrangement, which demonstrates the equivalence of the SI realizations in all participating countries. It acknowledges also the contributions of thousands of metrologists throughout the world to the CIPM MRA which in turn provides global support to major challenges such as trade and environmental protection.

EURAMET does not of course work in a vacuum and is actively strengthening its liaisons with other European and international organisations active in measurement, testing, accreditation and conformity assessment. European contacts include both the European Cooperation in Legal Metrology (WELMEC) and the Focus for Analytical Chemistry in Europe (EURACHEM) which have recently become Liaison Organisations with EURAMET. EURAMET is also cooperating more with European Cooperation for Accreditation (EA), EUROLAB (European Federation of National Associations of Measurement, Testing and Analytical Laboratories), and CEOC (European Confederation of Inspection Organisations) in coordination groups such as $4 \mathrm{E}+\mathrm{C}$ and PLG (Permanent Liaison Group) amongst these organisations, as well as being an active member of several EA groups (EA Laboratory Committee, EA Interlaboratory Comparisons, Quality Management Systems, etc). EURAMET is one of two organisations representing Metrology (together with WELMEC) in the EA Advisory Board. EURAMET is promoting the key role of the quality-assured measurements it delivers in the context of conformity assessment - in both the regulated and deregulated areas - as the European Commission modernises the 'New approach' for the marketing of products. [6]

\subsection{Key Comparisons}

Key comparisons, a 'proficiency testing' of the metrologists, are one 


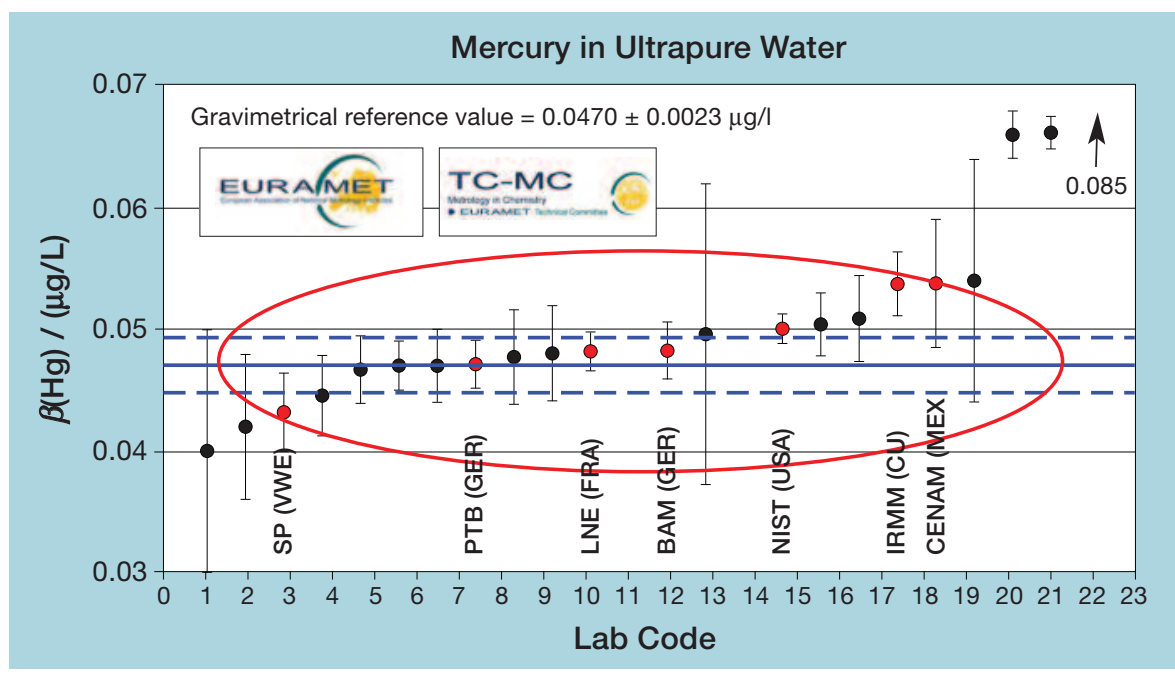

Figure 3. Some results from CCQM-P100.1/EURAMET 924 key comparison. [8]

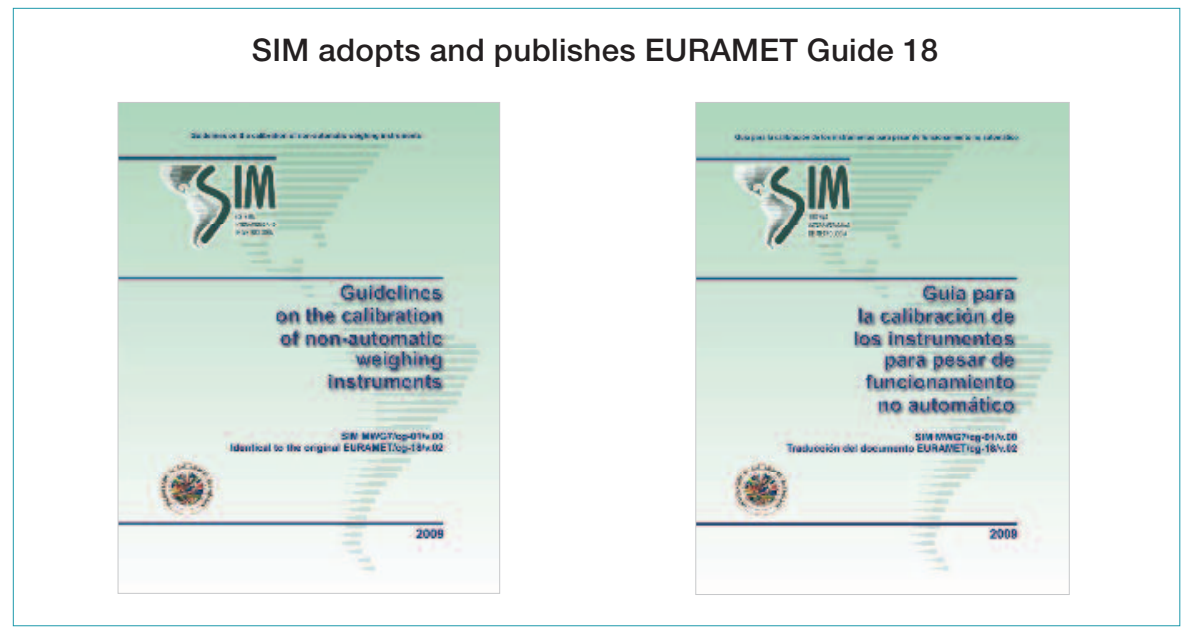

Figure 4. Adoption by the InterAmerican Metrology System (SIM) of a EURAMET guide on the calibration of non-automatic weighing instruments.

of the most important tools to demonstrate the mutual equivalence of different national metrology systems, at the same time constituting a collective learning process where participating laboratories can 'iron out' their differences when analysing comparison data.

Two examples of successful key comparisons involving EURAMET members are highlighted here.

\subsubsection{EURAMET.T-K7: Water Triple Point Cells}

This EURAMET key comparison of water triple point cells is a regional extension of the earlier CIPM Consultative Committee for Thermometry (CCT) key comparison CCT-K7 (2002-2004). Nine of the 24 participating NMIs in the EURAMET project had participated in CCT-K7, thereby ensuring robust linkage between the regional and global comparisons. [7]

These comparisons can be considered a powerful tool in confirming the impact of the recently refined definition of the water triple point temperature in terms of the Vienna Standard Mean Ocean Water (VSMOW). In the European comparison, the EURAMET.T-K7 reference value (Fig. 2) was found interestingly to be $65 \mathrm{~K}$ higher than CCT-K7 key comparison reference value (KCRV) (while agreeing within a few $\mathrm{K}$ with the best estimate of the SI unit).

\subsubsection{EURAMET 924: Water Monitoring}

This EURAMET key comparison is titled: "Development of a sustainable traceability and dissemination system providing Europe-wide comparable measurement results in water monitoring under the Water Framework Directive (2000/60/EC).” [8]

The European Water Framework Directive (WFD) [9] aims to ensure the good quality of surface, ground and coastal water in the EU by 2015. Towards this aim, the WFD requires comparable measurement results (Fig. 3) for assessments of water quality, with a priority list of substances $(\mathrm{Ni}, \mathrm{Cd}, \mathrm{Pb}$, $\mathrm{Hg}$ ) and referring to typical environmental quality standards, such as limits on the concentration of these substances (for example, the upper specification limits on $\mathrm{Hg}$ is set to $50 \mathrm{ng} / \mathrm{l})$.

\section{Metrology Knowledge Transfer (Activity C)}

The EURAMET organisation increasingly needs to interact and exchange metrological knowledge with its major stakeholder groups, both providers and customers of metrological resources and competence. In the broad sense of metrology knowledge transfer (KT) [10], EURAMET is clarifying its strategy for exchange with major groups of stakeholders, ranging from researchers in academia and industry to regulators and policy-makers in the context of conformity assessment. Included in KT activities are up-dating of the EURAMET website (www.euramet.org) and creation of the EURAMET Focus Group "Facilitating National Metrology Infrastructure Development." [2]

\subsection{Calibration Guides}

EURAMET aims to coordinate metroland \& training material both for its members and for industry. A series of calibration guides, earlier produced in collaboration with EA, has been reviewed and adapted to the new EURAMET organisation. These Guides fulfill an essential role, not only for secondary and industrial calibration laboratories but also for the NMIs themselves. Globally, there is an acknowledged lack of international guides of this kind. During 2009, the $\mathrm{RMO}$ of the Americas, the InterAmerican Metrology System (SIM), has for example (Fig. 4) adopted and translated an additional version in Spanish of the EURAMET Guide 18 on the calibration of non-automatic weighing instruments. 


\subsection{Interlaboratory Comparisons as a Learning Process}

Several EURAMET members function as 'Proficiency Test (PT) providers', that is, continuing a traditional and well-established role of national metrology institutes in support of thousands of secondary calibration laboratories and conformity assessment bodies such as testing labs in many sectors and technologies.

\subsection{Metrology Knowledge Transfer and the EMRP}

The major European Metrology Research Programme [3] is not just research but also includes an important element of metrology knowledge exchange. New measurement knowledge gleaned in EMRP joint research projects, for instance in this year's Metrology in Energy Call, needs to be exploited in several ways, such as the creation of new calibration and testing methods; new courses in the art of measurement; as well as research projects in collaboration with researchers outside the immediate NMI community. Indeed, the European Commission clearly specifies criteria against which the success of the EMRP is to be measured which include knowledge transfer issues such as: [11]

- Level of participation in the EMRP programme by outside researchers and research institutions.

- Increase in metrology capacity of metrology programmes at an early stage of development.

- Number and quality of training activities.

- Number and quality of activities related to metrology communication and diffusion.

\subsection{Conferences}

EURAMET continues to provide organisational support, together with several other major international metrology organisations, to the annual NCSLI Workshop and Symposium, as well as the International Congress of Metrology 2009, organised by the College Francais de Metrologie. [12]

\section{Conclusion and Plans}

For the near future, EURAMET is considering:

Strategy B (International Recognition)

At EURAMET level:

- Greater role in contributions to policy issues within Europe.

- Continued work with new criteria for accepting members and associates and procedures for on-site peer review visits.

\section{Strategy C (Knowledge Transfer)}

At CIPM MRA/RMO level:

- Supporting new RMO Intra-Africa Metrology System (AFRIMETS) alongside other established RMOs.

- BIPM initiative: Forum on Coordination of NMI International Activities.

In summary, this paper has reported on progress in the new EURAMET organisation to enable Europe to respond to the growing demands for cutting-edge metrology as a tool for innovation, scientific research and support for policy, particularly in emerging technological areas and in meeting the major challenges of society.

\section{Acknowledgments}

The support of EURAMET, especially the Board of Directors, Technical Committee Chairs and all parts of the EURAMET Secretariat is gratefully acknowledged. Information and permission to quote the results of the EURAMET key comparisons cited has been kindly provided by the EURAMET Technical Committee Chairs Mr. Buck and Mr. Güttler, for the Temperature and Metrology in Chemistry Committees, respectively.

\section{References}

[1] EURAMET information is available at: www.euramet.org.

[2] W. Schmid and A. Leitner, "Cooperation in development of national metrology infrastructure within EURAMET," NCSLI Measure, vol. 4, no. 4, pp. 36-42, 2009.

[3] A. Henson, "The European Metrology Research Programme in Action," NCSLI Measure, vol. 4, no. 4, pp. 28-35, 2009.

[4] "EURAMET procedures and review criteria for CMCs," Guide No. 8, EURAMET, 2008. (www.euramet.org/index.php?id=guides)

[5] World Metrology Day 2009: www.worldmetrologyday.org/index.html.

[6] New Approach 2008: http://ec.europa.eu/enterprise/newapproach/index_en.htm

[7] A. Peruzzi, R. Bosma, O. Kerkhof, R. Peter, M.D. del Campo Maldonado, M. Smid, D. Zvizdic, M.B. Nielsen, M. Anagnostou, E. Grudnewicz, M. Nedea, P.P.M. Steur, E. Filipe, I. Lobo, I. Antonsen, E. Renaot, T. Weckstrom, J. Bojkovski, E. Turzó-András, M. White, E. Tegeler, M. Dobre, J. Ranostaj, A. Kartal Dogan, V. Augevicius, A. Pokhodun and S. Simic, "Final Report on EUROMET.T-K7: Key comparison of water triple point cells," Metrologia, vol. 46, p. 03001, 2009. (doi: 10.1088/00261394/46/1 A/03001)

[8] EURAMET 924, "Development of a sustainable traceability and dissemination system providing Europe-wide comparable measurement results in water monitoring under the Water Framework Directive (2000/60/EC)," EUROMET.QM-S2 Final Report KCDB and Metrologia Technical Supplement (in press) (www.euramet.org/index.php?id=tc-projects\&no_cache $=1 \&$ ctcp projects[sword][title]=\&ctcp_projects[sword][refid]=924)

[9] Water Framework Directive (2000/60/EC), EU Commission http://ec.europa.eu/environment/water/water-framework/index_en.html.

[10] G. Harris and L. R. Pendrill, "Comparing and Contrasting Studies of Metrology Education and Training in Europe and North America," NCSLI Measure, vol. 3, no. 2, pp 38-45, 2008.

[11] European Parliament legislative resolution of 22 April 2009 on Proposal for decision of European Parliament and of Council on participation by the Community in a European metrology research and development programme undertaken by several Member States. (COM(2008)0814 - C6-0468/2008 - 2008/0230(COD)) www.europarl.europa.eu/sides/getDoc.do?type $=$ TA\&reference $=P$ 6-TA-2009-0224\&language $=\mathrm{EN} \&$ ring $=$ A6-2009-0221.

[12] International Congress of Metrology 2009, www.metrologie2009.com/index_en.php. 